This is the final peer-reviewed accepted manuscript of:

LAZZARI, MAURIZIO; BETTINI, SIMONE; MILANI, LILIANA; MAURIZII, MARIA GABRIELLA; FRANCESCHINI,

VALERIA: Differential response of olfactory sensory neuron populations to copper ion exposure in zebrafish.

AQUATIC TOXICOLOGY 183. 0166-445X

DOI: 10.1016/j.aquatox.2016.12.012

The final published version is available online at:

http://dx.doi.org/10.1016/i.aquatox.2016.12.012

Rights / License:

The terms and conditions for the reuse of this version of the manuscript are specified in the publishing policy. For all terms of use and more information see the publisher's website.

This item was downloaded from IRIS Università di Bologna (https://cris.unibo.it/)

When citing, please refer to the published version. 


\title{
Differential response of olfactory sensory neuron populations to copper ion exposure in zebrafish
}

\author{
Maurizio Lazzari ${ }^{*}, 1$, Simone Bettini ${ }^{1}$, Liliana Milani, Maria Gabriella Maurizii, \\ Valeria Franceschini
}

Department of Biological, Geological and Environmental Sciences, University of Bologna, 40126 Bologna, Italy

\section{A R T I C L E I N F O}

Keywords:

Copper ions

Olfactory epithelium

Olfactory sensory neurons

Crypt cells

Olfactory recovery

Zebrafish

Immunohistochemistry

\begin{abstract}
A B S T R A C T
The peripheral olfactory system of fish is in direct contact with the external aqueous environment, so dissolved contaminants can easily impair sensory functions and cause neurobehavioral injuries. The olfac-tory epithelium of fish is arranged in lamellae forming a rosette in the olfactory cavity and contains three main types of olfactory sensory neurons (OSNs): ciliated (cOSNs) and microvillous olfactory sensory neu-rons (mOSNs), common to all vertebrates, and a third minor group of olfactory neurons, crypt cells, absent in tetrapods. Since copper is a ubiquitously diffusing olfactory toxicant and a spreading contaminant in urban runoff, we investigated the effect of low copper concentration on the three different OSNs in the olfactory epithelium of zebrafish, a model system widely used in biological research. Image analysis was applied for morphometry and quantification of immunohistochemically detected OSNs. Copper exposure resulted in an evident decrease in olfactory epithelium thickness. Moreover, after exposure, the lamellae of the dorsal and ventral halves of the olfactory rosettes showed a different increase in their sensory areas, suggesting a lateral migration of new cells into non-sensory regions. The results of the present study provide clear evidence of a differential response of the three neural cell populations of zebrafish olfactory mucosa after $96 \mathrm{~h}$ of exposure to copper ions at the sublethal concentration of $30 \mu \mathrm{g} \mathrm{L}^{-1}$. Densit-ometric values of cONS, immunostained with anti-G $\alpha$ olf, decreased of about $60 \%$ compared to the control. When the fish were transferred to water without copper addition and examined after 3, 10 and 30 days, we observed a partial restoration of anti-G $\alpha$ olf staining intensity to normal condition. The recovery of cOSNs appeared sustained by neuronal proliferation, quantified with anti-PCNA immunostaining, in par-ticular in the early days after exposure. The densitometric analysis applied to mOSNs, immunostained with anti-TRPC2, revealed a statistically significant decrease of about 30\% compared to the control. For cOSNs and mOSNs, the decrement in staining intensity may be indicative of cell death, but reduction in antigen expression may not be excluded. In the post-exposure period of 1 month we did not find recov-ery of mOSNs. We hypothesize that cOSNs are more sensitive than mOSNs to copper treatment, but also more prompted to tissue repair. Anti-TrkA-immunopositive crypt cells appeared not to be affected by copper exposure since statistical analysis excluded any significant difference between the control and treated fish. Comparative studies on OSNs would greatly enhance our understanding of the mechanisms of olfaction.
\end{abstract}

\section{Introduction}

Aquatic animals depend on chemical information from the environment in order to carry out vital life processes (Pyle and Mirza, 2007). Olfaction is an essential sense for detection and evaluation of the environment in all vertebrates, including teleosts (Green and

\footnotetext{
* Corresponding author at: Department of Biological, Geological and Environmen-tal Sciences, University of Bologna, Via Selmi 3, 40126, Bologna, Italy. E-mail address: maurizio.lazzari@unibo.it (M. Lazzari).

${ }^{1}$ These two authors are co-first authors of the paper.
}

Zielinski, 2013). Other than information on the position and composition of food, this chemical sense permits the recognition of predators and social cues such as pheromones (Wyatt, 2010).

The olfactory system of teleosts can discriminate among an assortment of odorant molecules dissolved in water, including amino acids, bile salts, polyamines, nucleotides, prostaglandins, and sex steroids. Chemical information on the environment is transmitted from the olfactory organ to the brain, influencing alarm response, predator avoidance, food finding, social communication, reproductive activity, and homing migration (Eisthen and Polese, 2007; Hamdani and Døving, 2007; Sorensen and Caprio, 1998). 
Teleost fishes, which are a division of ray-finned fishes, include over 23,000 species (Nelson, 2006). As in the other fishes, the olfactory epithelium in ray-finned fishes is organized in a rosette of lamellae radiating outward from a central raphe. Both the shape and complexity of lamellar organization differ among species (Hansen and Zielinski, 2005; Yamamoto, 1982; Zeiske et al., 1992). Unlike tetrapods, the olfactory system of teleosts lacks a separate vomeronasal organ in addition to a main olfactory system. Teleosts possess a single olfactory epithelium (OE) arranged in lamellae in the olfactory cavities that are positioned dorsally on each side of the head. A great number of olfactory sensory neurons (OSNs) detects odorants and sends odor information into the brain.

The two main types of vertebrate OSNs are ciliated (cOSNs) and microvillous olfactory sensory neurons (mOSNs) (reviewed in Eisthen, 1992) which in teleosts and mammals express olfactory receptors of the OR and TAAR gene families, also named V1R- and V2R-type genes, respectively (Oka et al., 2012). In addition, elasmo-branchs, cladistians and teleosts possess one minor group of OSNs, crypt cells (Ferrando et al., 2006, 2007, 2011; Hansen and Finger, 2000), which apparently express only a single olfactory receptor, the V1R-related ORA4 (Oka et al., 2012), believed to be absent in tetrapods (Hansen and Finger, 2000; Laberge and Hara, 2001). Cil-iated, microvillous, and crypt-type OSNs are broadly present in ray-finned fishes, but the distribution of each cell type is some-what variable. By way of the olfactory nerve, axons of ORNs reach the olfactory bulb where they contact dendrites of mitral cells and local interneurons in the glomerular layer, giving rise to complex neuropil structures, glomeruli, which display a stereotyped orga-nization and bilateral symmetry (Baier and Korsching, 1994). In the olfactory bulb, olfactory glomeruli represent the first central nervous station for odor processing, i.e. the first relay station in the olfactory pathway (Gayoso et al., 2012; Hamdani and Døving, 2007).

The discharge of industrial and domestic wastewater is the threat endangering aquatic environments that has the most significant impact on freshwater ecosystems, as well as agricultural production and human health (Katagi, 2010; Klečka et al., 2010; Schwarzenbach et al., 2010). Thus, constant monitoring is essential to ensure prompt intervention whenever hazardous waste discharge events occur. Due to their biodiversity, population structure and health conditions, fish have been judged ideal biomonitor-ing organisms. Fish have been proposed as organisms for in vivo toxicity assays (Cardwell et al., 1976). Normal embryo conditions, such as egg hatchability and embryo growth and survival, can be also used as monitoring parameters (Lammer et al., 2009a,b). A common approach to assess water quality is also represented by quantifying in fish the activity of enzymatic defenses. Recent works demonstrated that contamination of aquatic environments, i.e. exposure to neurotoxic chemicals such as heavy metals, can impair chemosensory functions, a process recently named 'info-disruption'(Lürling and Scheffer, 2007), and lead to a loss of olfaction in vertebrates (Baldwin et al., 2011; Bondier et al., 2008).

The fish peripheral olfactory system is in direct contact with the external environment. Therefore, it is directly exposed to dissolved contaminants, which can impair peripheral neurological function (Laberge and Hara, 2001; Tierney et al., 2010). In fish, neurobehavioral injuries induced by metals are extremely problematic due to the alteration and possible loss of olfactory-controlled behaviors basic to survival (Baldwin et al., 2003; Sandahl et al., 2007; Scott et al., 2003). Copper is a ubiquitously diffusing olfactory toxicant and a spreading contaminant in urban runoff at low concentra-tions, varying from 3 to $64 \mathrm{ppb}$ (Soller et al., 2005). Specifically, vehicle emissions, pesticides, and industrial utilizations are major sources of $\mathrm{Cu}$ in runoff (Davis et al., 2001; Good, 1993). In par-ticular, copper exerts its neurotoxic effect on fish olfaction (Shaw and Handy, 2011). There is evidence that exposure to sublethal copper levels results in the loss of chemosensory function, which affects predator-avoidance behavior (McIntyre et al., 2008). The exact mechanisms are not yet completely understood and are still under investigation (Kiaune and Singhasemanon, 2011).

The aim of the present work is to investigate the effect of low concentration of copper ions $\left(\mathrm{Cu}^{2+}\right)$ on the three different OSNs present in the olfactory epithelium of teleost fish, which are ciliated, microvillous, and crypt neurons. Image analysis quantification of immunohistochemically detected neuronal molecular markers was applied to differentiate neuronal response to $\mathrm{Cu}^{2+}$ exposure.

The evaluation of the effect of metals in fish is complicated also by the different toxicity reported in the literature concerning different species and different experimental conditions (Azizishirazi et al., 2013; Song et al., 2015; Tierney et al., 2010; Wang et al., 2013a). The present study was carried out on zebrafish (the freshwater fish Danio rerio), which is a model system widely used in embryological, neurological and genetic studies and also possesses numerous advantages in toxicity assessment such as reduced hous-ing costs and small size, which allows quantitative analysis on a large number of slides. (Hill et al., 2005; Miyasaka et al., 2013; Segner, 2009). Furthermore, zebrafish olfactory system, which is histologically comparable to those of other vertebrates, is largely mentioned in the literature (see Tierney et al., 2010), and cells constituting its neuroepithelium are immunologically well characterized (Braubach et al., 2012; Gayoso et al., 2011; Germanà et al., 2007).

\section{Materials and methods}

\subsection{Animals}

Forty adults of Danio rerio (Hamilton, 1882), 6-8 months old and about $4 \mathrm{~cm}$ in total length, were purchased from the Coral Aquar-ium, Bologna, Italy. They were acclimatised in tanks containing a 1:2 mixture of dechlorinated tap water and distilled water for 30 days, at $25^{\circ} \mathrm{C}$ in a $12: 12 \mathrm{~h}$ light:dark cycle. They were fed twice a day with commercial food distributed by an automatic fish feeder. All procedures conformed to the guidelines of European Communi-ties Council Directive (86/609/CEE), the current Italian legislation regarding the use and care of animals, and the guidelines issued by the US National Institutes of Health. This study was approved by the Scientific Ethics Committee of the University of Bologna (protocol no. 17/79/2014).

\subsection{Copper exposure}

In the US EPA ECOTOX database (http://cfpub.epa.gov/ecotox/ ), the lethal concentration $50\left(\mathrm{LC}_{50}\right)$ for copper sulfate measured in zebrafish embryos exposed for $48 \mathrm{~h}$ was $270 \mu \mathrm{g} \mathrm{L}^{-1}$. In the present study, the concentration of $117 \mu \mathrm{g} \mathrm{L}^{-1}$ of copper sulfate, corresponding to $30 \mu \mathrm{g} \mathrm{L}^{-1}$ of $\mathrm{Cu}^{2+}$, supposed to be sublethal, was employed. Thirty-two fish were moved to $10 \mathrm{~L}$ tanks containing $30 \mu$ $\mathrm{g} \mathrm{L}^{-1}$ of $\mathrm{Cu}^{2+}$ from copper sulfate (Honeywell, Hanover, D) dissolved in water. A static/renewal system was applied: fish were moved to new tanks containing freshly prepared $\mathrm{Cu}^{2+}$ solution every $24 \mathrm{~h}$. $\mathrm{Cu}^{2+}$ olfactory toxicity was evaluated after standard 4 day (96 h) exposure, as common use in acute toxicity tests. The water parameters of the acclimatization tank as well as control and treatment tanks were monitored. Representative values are shown in Table 1. The treated animals were divided into four groups, eight specimens each: T0, sacrificed immediately after the $96 \mathrm{~h}$ exposure, T3, T10 and T30, sacrificed after 3, 10 and 30 days of recovery, respectively. For recovery, fish were transferred to new $10 \mathrm{~L}$ tanks filled with water without addition of copper. Two control fish were sacrificed with every group of treated animals ( 8 fish in total). 
Table 1

Water parameters of acclimatization, control, $\mathrm{Cu}^{2+}$ exposure, and recovery tanks.

\begin{tabular}{|c|c|c|c|c|c|}
\hline & $\mathrm{NO}_{3} \mathrm{mg} \mathrm{L}^{-1}$ & $\mathrm{NO}_{2} \mathrm{mg} \mathrm{L}^{-1}$ & $\mathrm{GH} \mathrm{dH}$ & $\mathrm{KH} \mathrm{dH}$ & $\mathrm{pH}$ \\
\hline Acclimatization tanks, new water, before fish insertion & $<25$ & $<0.5$ & $14-21^{\circ}$ & 10 & $7.4-7.5$ \\
\hline Acclimatization tanks, after $24 \mathrm{~h}$ fish presence, before water change & $<25$ & $<0.5$ & $14-21^{\circ}$ & 10 & $7.3-7.4$ \\
\hline Control tanks, new water, before fish insertion & $<25$ & $<0.5$ & $14-21^{\circ}$ & 10 & $7.4-7.5$ \\
\hline Control tanks, after $24 \mathrm{~h}$ fish presence, before water change & $<25$ & $<0.5$ & $14-21^{\circ}$ & 10 & $7.3-7.4$ \\
\hline Exposure tanks, new water, before fish insertion & $<25$ & $<0.5$ & $14-21^{\circ}$ & 10 & $7.4-7.5$ \\
\hline Exposure tanks, after $24 \mathrm{~h}$ fish presence, before water change & $<25$ & $<0.5$ & $14-21^{\circ}$ & 10 & $7.3-7.4$ \\
\hline Recovery tanks, new water, before fish insertion & $<25$ & $<0.5$ & $14-21^{\circ}$ & 10 & $7.4-7.5$ \\
\hline Recovery tanks, after $24 \mathrm{~h}$ fish presence, before water change & $<25$ & $<0.5$ & $14-21^{\circ}$ & 10 & $7.3-7.4$ \\
\hline
\end{tabular}

$\mathrm{dH}$, degree of hardness; GH, general hardness; KH, carbonate hardness.

\subsection{Tissue}

Animals were anesthetized with $0.1 \%$ 3-aminobenzoic acid ethyl ester (MS-222, Sigma, St. Louis MO, USA) and killed by decapita-tion. After removal of the dorsal cranium, the heads were promptly immersed in a modified Bouin's fixative solution, consisting of a saturated aqueous solution of picric acid and formalin (ratio 3:1), for $24 \mathrm{~h}$ at room temperature.

After fixation and picric acid removal, the heads were decalcified in $0.25 \mathrm{M}$ EDTA in $0.1 \mathrm{M}$ phosphate buffer, $\mathrm{pH} 7.4$, for 9 days at room temperature, dehydrated and then embedded in Paraplast Plus (Leica Biosystems, Richmond, IL, USA; melting point 55-57 $\left.{ }^{\circ} \mathrm{C}\right)$. Frontal serial $5 \mu \mathrm{m}$-thick sections were collected on silanecoated slides (Sigma). Adjacent slides were used for immunohistochemical detection.

\subsection{Immunohistochemistry}

Details are reported in Lazzari et al., 2016. Deparaffinized and rehydrated sections were incubated separately overnight with six primary antibodies, in a moist chamber on a floating plate at $4{ }^{\circ} \mathrm{C}$ : a) monoclonal mouse anti-proliferating cell nuclear antigen (antiPCNA; Clone PC10; P 8825; Sigma; used dilution 1:500) to detect dividing cells (Bettini et al., 2016; Iqbal and Byrd-Jacobs, 2010); b) rabbit polyclonal anti- $G_{\alpha o l f}$ (sc-385; Santa Cruz Biotechnology, Santa Cruz, CA, USA; used dilution 1:500), a marker for ciliated olfactory neurons (Braubach et al., 2012; Gayoso et al., 2011); c) rabbit polyclonal anti-calretinin (AB5054; Chemicon International, Temecula, CA, USA; used dilution 1:1,000), detecting a heterogeneous population of ciliated and microvillous olfactory neurons (Bettini et al., 2016); d) mouse monoclonal anti-human neuronal protein HuC/HuD (anti-HuC/D; Clone 16A11; A-21271; Molecular Probes, Eugene, OR, USA; used dilution 1:100), a nuclear marker of immature and mature neurons (Bettini et al., 2016; Iqbal and ByrdJacobs, 2010); e) rabbit polyclonal anti-tyrosine protein kinase $A$ (anti-TrkA; sc-118; Santa Cruz Biotechnology; used dilution 1:100), a marker for crypt olfactory cells (Ahuja et al., 2013; Bettini et al., 2016); f) rabbit polyclonal anti-transient receptor potential cation channel, subfamily C, member 2 (anti-TRPC2; LS-C95010; LifeS-pan BioSciences, Seattle, WA, USA; used dilution 1:200), a marker for microvillous olfactory neurons (Bettini et al., 2016). Sections were incubated for $1 \mathrm{~h} 30 \mathrm{~min}$ in the secondary antibody: HRP-conjugated goat anti-mouse IgG (A4416; Sigma; used dilution $1: 100)$ for monoclonal primary antibodies, and HRP-conjugated goat anti-rabbit IgG (PI-1000; Vector Laboratories, Burlingame, CA, USA; used dilution 1:100) for polyclonal primary antibodies. The immunoreaction was visualized using 0.1\% 3,3-diaminobenzidine (DAB; Sigma) as substrate. Nuclear counterstaining with Gill's hematoxylin was carried out to enhance the contrast, with the exception of sections incubated with anti-PCNA antibody. AntiTRPC2 is specific against zebrafish antigens while all the other antibodies here employed were previously successfully tested by other authors on zebrafish olfactory organ. Sections were then dehydrated in ethanol, cleared in xylene and coverslipped with Per- mount (Fisher Scientific, Pittsburgh, PA). Negative controls for the specificity of the immunostaining were obtained by omission of the primary antibodies, replaced by $3 \%$ normal goat serum. Sections from control fish were used as positive controls.

\subsection{Image acquisition, quantification and statistical analysis}

Bright-field images of the sections were taken using an Olympus BH-2 microscope (Olympus Italia, Segrate, Italy) equipped with a BEL BlackL 5000 digital camera (BEL Engineering, Monza, Italy). All images used for quantification were taken under the same light conditions. Adobe Photoshop CS3 (Adobe Systems, San Jose, CA, USA) was used to assemble the micrographs. The micrographs were rotated, resized, added with bars, letters and symbols, and adjusted for brightness and contrast, but the content was not altered. Mea-surements were taken on semi-serial sections using ImageJ $1.50 \mathrm{~g}$ software (https://imagej.nih.gov/ij/) and restricted to the sensory region of lamellae, easily distinguishable from non-sensory regions by the staining pattern.

In calretinin-immunolabelled sections, epithelial thickness was measured from the basal lamina to the apical surface, excluding cilia and microvilli. For each section, the value of epithelial thickness was calculated as the average of nine measurements, three values from each of three random lamellae. Sensory and non-sensory epithelial areas were calculated in three lamellae per section and averaged. The two regions were easily distinguishable due to both labelling and presence of long cilia on the surface of non-sensory areas.

The densities of TrkA- and PCNA-positive cells were estimated through physical disector method (Bettini et al., 2016). Briefly: serial pairs of sections were collected and only the cells that were observable in the first section of the pair, but not in the second one were counted. Cells were counted in three lamellae per section using the Cell Counter plugin in ImageJ.

In the quantitative analysis of $\mathrm{HuC} / \mathrm{D}, \mathrm{G}_{\alpha \mathrm{olf}}$ and TRPC2 immunolabelling, it was very difficult to count positive cells, since $G_{\alpha o l f}$ and TRPC2 antigens appear in limited cytoplasmic portions, while $\mathrm{HuC} /$ $\mathrm{D}$ positive cells were a lot and too close to each other to apply disector method correctly. Therefore, we compared the immunostaining intensity, which was evaluated as an indirect index of the number of immunopositive cells in a specific lamellar region and measured through Optical Density (OD). The OD of three lamellae per section was calculated according to the method of Iqbal and Byrd-Jacobs (2010) and averaged. When the sections were counterstained with hematoxylin, the Color Deconvolution plugin of Image J was used for hematoxylin and DAB separation. Average grey values were obtained in the sensory regions. Background values were evaluated from unstained areas of the tissue. Finally, the fol-lowing formula was applied: $\mathrm{OD}=\log$ (background grey value/ROI grey value), where ROI is region of interest.

For each antigen, mean values of zebrafish groups were compared using ANOVA and the LSD post hoc test. In the bar graphs, data were reported as mean values \pm standard deviations. 


\section{Results}

In zebrafish, the treatment with $\mathrm{Cu}^{2+}$ resulted in no microanatomical effects: olfactory rosettes preserved their morphology and their lamellae did not show tissue disruption, metaplasia or changes in intraepithelial glands. No animal died during either exposure or recovery.

In the image analysis performed on rosette sections, anticalretinin antibody, which stains bodies and dendrites of various OSNs, revealed that in $\mathrm{TO}$ and $\mathrm{T} 3$ the thickness of the sensory epithe-lium from the basal lamina to the free surface was decreased, about $7 \%$ and $4 \%$ compared to the control, respectively (Fig. 1a, b). In T10 and T30, the epithelium thickness was statistically equivalent to the control. In some $\mathrm{Cu}^{2+}$-treated specimens, narrow immunoneg-ative zones, which therefore appeared lacking OSNs, interrupted olfactory epithelial continuity. In anti-calretinin-stained sections, image analysis was also applied to observe the ratio between sen-sory and nonsensory epithelium areas in the lamellae of olfactory rosette (Fig. 1c, d). In particular, when the ratio was calculated in the lamellae of the dorsal half of the rosette, a significant increase was found in T30 specimens, about $37 \%$ compared to the control (Fig. 1c). When the analysis was applied to the lamellae of the ven-tral half of the rosette, a significant increase of the ratio was already observed in T0, about $84 \%$ compared to the control, and the value remained statistically unchanged during recovery (Fig. 1d).

In sections stained with anti-HU antibody, no significant change in total neurons was observed between treated specimens com-pared to controls (Fig. 2a, b).

The digital image analysis of sections treated with the other antibodies revealed the response of the different neuronal subpopulations of the OE exposed to copper ions.

In the sections treated with anti- $G_{\alpha o l f}$ antibody, the immunopositivity was mainly located in the dendritic apical knobs and cilia at the free surface of the OE (Fig. 3a). In T0 spec-imens, the staining density decreases significantly after copper ion exposure, about 59\% compared to the control (Fig. 3b). T3-T30 specimens showed significant staining increase compared to $\mathrm{T} 0$, but these values remained statistically lower than the control and T3, T10 and T30 were not significantly different between each other.

In the OE, anti-TRPC2 antibody stained dendrite endings and microvilli of mOSNs (Fig. 4a). All treated specimens had densitometric values significantly lower than the control, about $30 \%, 20 \%$, $10 \%$, and $30 \%$ for T0, T3, T10, and T30, respectively (Fig. 4b). Val-ues appeared statistically homogeneous when the comparison was between treated specimens.

The third subpopulation of OSNs consisted of crypt cells. Crypt cells are big neurons, irregularly distributed along the epithelium of the olfactory lamellae. Their number is lower compared to cOSN and mOSN subpopulations. Therefore, in digital image analysis, the choice method was cell counting after immunolabelling with antiTrKA antibody instead of color densitometry (Fig. 5a). The population of crypt cells showed no statistically significant change in the four stages considered in the post exposure period (Fig. 5b).

In the damaged $\mathrm{OE}$, the recovery of olfactory cell populations is promoted by an increase in proliferative events, just the same occurring also in physiological conditions. Therefore, in the lamellar sensory epithelium, the count of PCNA-immunopositive cells was used to assess mitotic events following copper ion exposure from T0 to T30 (Fig. 6a). Statistical analysis pointed out a significant increase in T0 and T3, about 154 and 167\% compared to the control, respectively, whereas T10 and T30 did not statistically differ from the control value (Fig. 6b).

\section{Discussion}

In the olfactory epithelium of zebrafish, three main populations of OSNs are found by means of immunohistochemical detection of several molecular markers. The results of the present study provide clear evidence of a differential response of the neural cell popula-tions of zebrafish olfactory mucosa to environmental $\mathrm{Cu}^{2+}$ present at the sublethal concentration of $30 \mu \mathrm{g} \mathrm{L}^{-1}$.
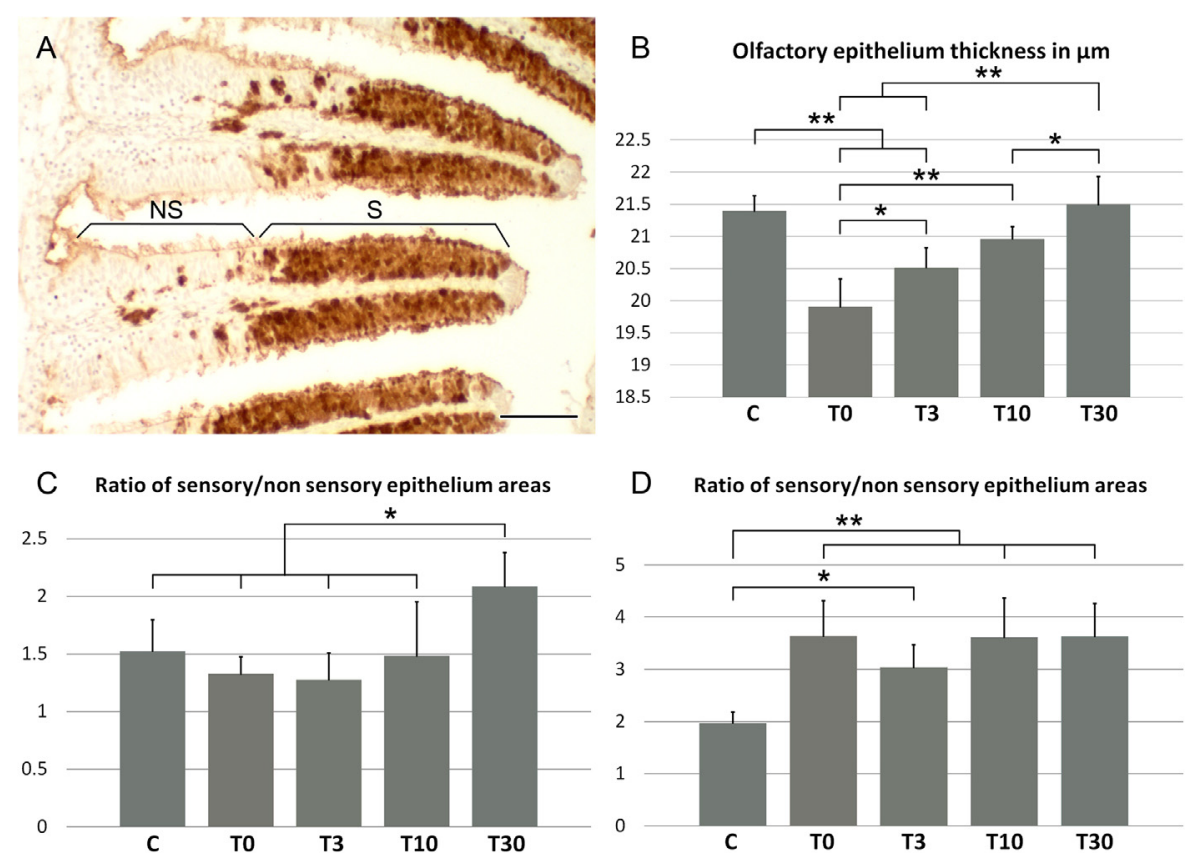

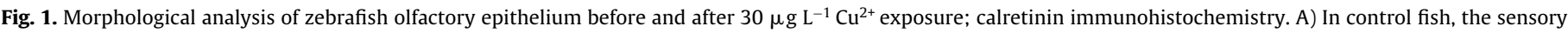

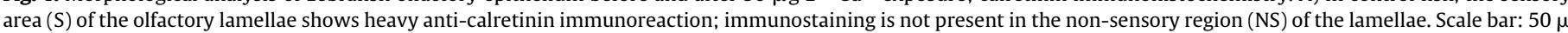

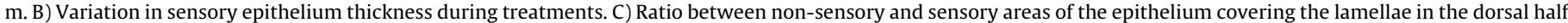

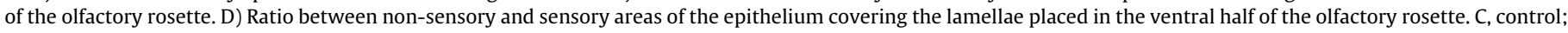
T0, 0 days of recovery; T3, 3 days of recovery; T10, 10 days of recovery; T30, 30 days of recovery. Asterisks indicate significant differences: ${ }^{*}, \mathrm{P}<0.05 ;{ }^{* *}, \mathrm{P}<0.01$. 


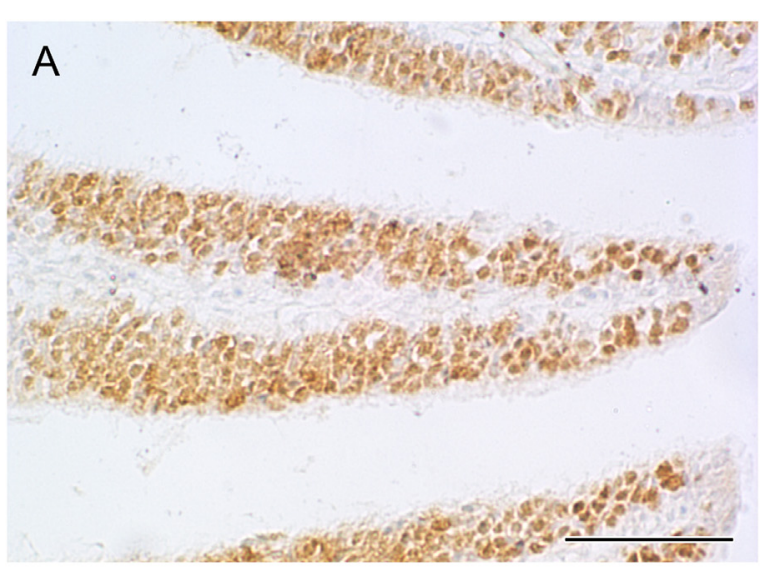

$B$ OD values for Hu C/D immunoreactivity

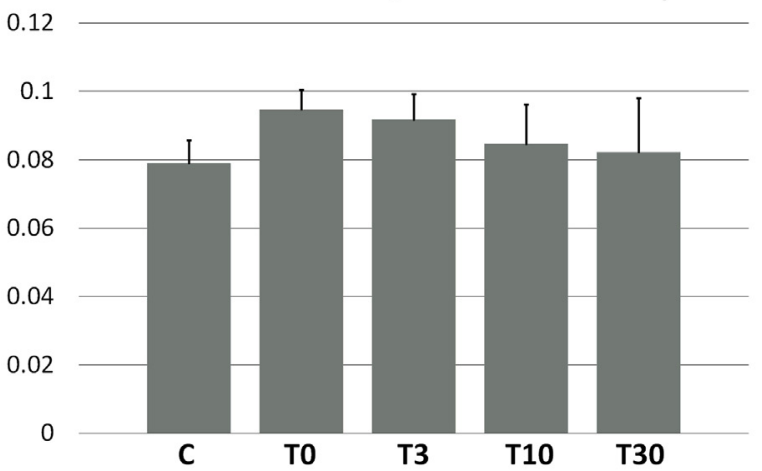

Fig. 2. HuC/D immunohistochemistry in zebrafish olfactory epithelium before and after $30 \mu \mathrm{g} \mathrm{L}^{-1} \mathrm{Cu}^{2+}$ exposure. A) Along the sensory regions in the olfactory lamellae of control fish, all the neurons show clear immunopositive cell bodies. Scale bar: $50 \mu \mathrm{m}$. B) Optical density analysis of the olfactory epithelium and comparison between control and treated groups. No significant difference results from the statistical analysis of data. C, control; T0, 0 days of recovery; T3, 3 days of recovery; $\mathrm{T} 10,10$ days of recovery; $\mathrm{T} 30,30$ days of recovery.

In our experiments, cOSNs are affected by $\mathrm{Cu}^{2+}$ showing densitometric values of immunostaining decreasing by about $60 \%$ compared to the control. The differences in the optical density of the immunostaining could be related to cell death observed in previous works (Kolmacov et al., 2009; Sovová et al., 2014; Wang et al., 2013b). When treated fish are transferred to water without addi-tion of copper, our densitometric measures indicate that a slow recovery takes place and it is already statistically appreciable after 3 days and more evident after 10 days. The recovery rate did not speed up, as T30 is not statistically different from T10. Therefore, we can suppose that the restoration of a normal $\mathrm{G} \alpha$ olf immunostaining pattern, if possible, would take more than one month.

In goldfish (Carassius auratus), sublethal $\mathrm{Cu}^{2+}$ exposure $(100 \mu$ $\mathrm{M}$ ) is reported neither to alter appreciably nor to eliminate mOSNs and their microvilli (Kolmacov et al., 2009). Accordingly, in our treated specimens, these apical processes are still visible and immunostained. However, the densitometric analysis for antiTRPC2 immunostaining revealed a statistically significant decrease, of about $30 \%$, compared to the control. Also for mOSNs, the differ-ences in the optical density could be indicative of cell death and, therefore, of some differences between the two species. In their review, Tierney et al. (2010) concluded that copper exposure causes morphological changes in the olfactory epithelium of salmonids ranging from slight (ciliary loss) to severe (OSNs death). In zebrafish mOSNs at T0, the densitometric reduction compared to the con-trol is about a half of that measured for cOSNs. Therefore, cOSNs appear more affected than mOSNs, and the difference between
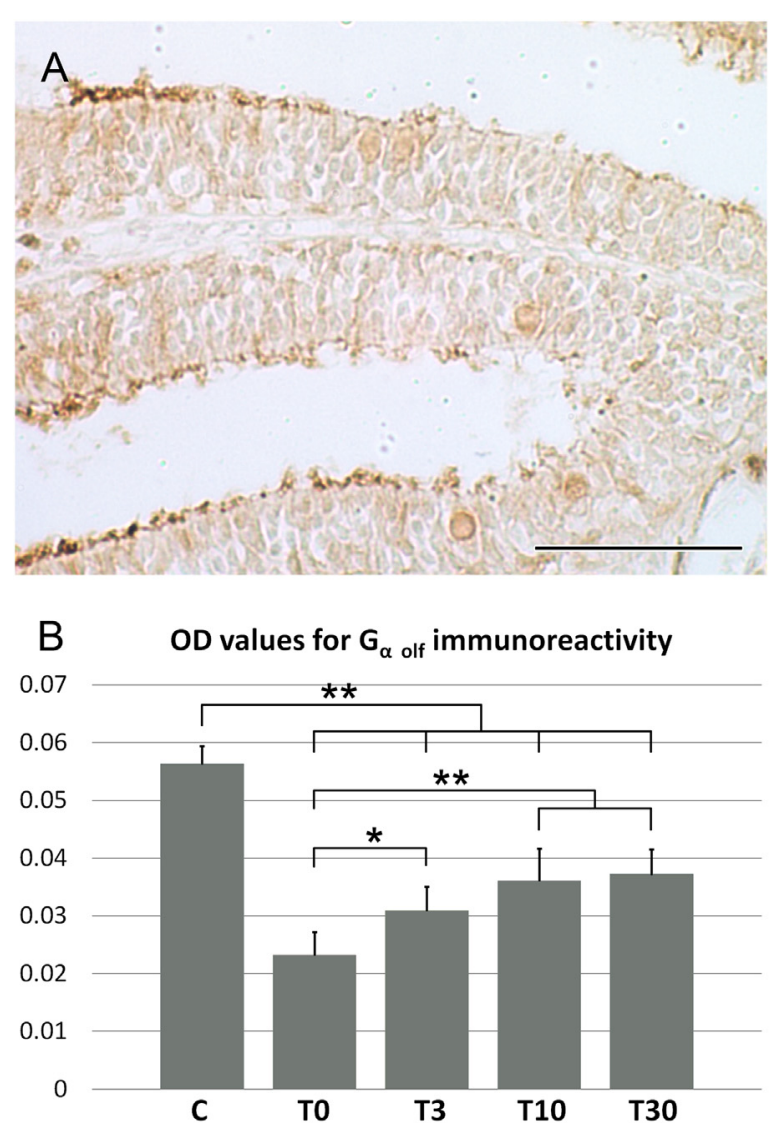

Fig. 3. $G_{\alpha o l f}$ immunohistochemistry in zebrafish olfactory epithelium before and after $30 \mu \mathrm{g} \mathrm{L}^{-1} \mathrm{Cu}^{2+}$ exposure. A) Along the sensory regions in the olfactory lamellae of control fish, the superficial zone of the olfactory epithelium contains the receptor cell knobs which show different staining intensity for $G \alpha$ olf immunohistochemistry. Scale bar: $50 \mu \mathrm{m}$. B) Optical density analysis of the olfactory epithelium surface and comparison between control and treated groups. C, control; T0, 0 days of recovery; T3, 3 days of recovery; T10, 10 days of recovery; T30, 30 days of recovery. Asterisks indicate significant differences: ${ }^{*}, \mathrm{P}<0.05$; ${ }^{* *}, \mathrm{P}<$ 0.01 .

them turns out to be greater than in goldfish (Kolmacov et al., 2009). The observation that copper affects cOSNs relative to mOSNs has been previously reported by Dew et al. (2014) using a functional approach with electro-olfactograms. In the postexposure period of 1 month, mOSNs did not show statistically significant increase in immunostaining; consequently, we did not found recovery of mOSNs. Their limited or complete recovery in longer times remains speculative.

In our study, we have an indirect evidence of a decrease in the number of cOSNs and mOSNs since densitometric analysis reveals only a decrease in immunostaining intensity. According to Kolmacov et al. (2009), copper ion exposure could result in alteration or loss of cilia. Therefore, in zebrafish, the decrease in immunostaining signal could be caused by alterations in the morphology of dendrite endings (reduction of cilia and microvilli) and not exclusively by cell death (Jenkins et al., 2009). In accordance with Tilton et al. $(2008,2011)$ and Wang et al. (2013c), reduction in antigen expression without cell death or morphology alteration could be another explanation.

The third population of OSNs consists of crypt cells (Ferrando et al., 2006; Gayoso et al., 2011, 2012; Hansen and Finger, 2000; Hansen and Zeiske, 1998; Lazzari et al., 2007). Previous immunohistochemical studies on these specific cells were performed using S100 as molecular marker (Braubach et al., 2012; Germanà et al., 2004; Sato et al., 2005). However, anti-S100 antibody was reported to stain not only crypt neurons but also some other cells (Germanà 


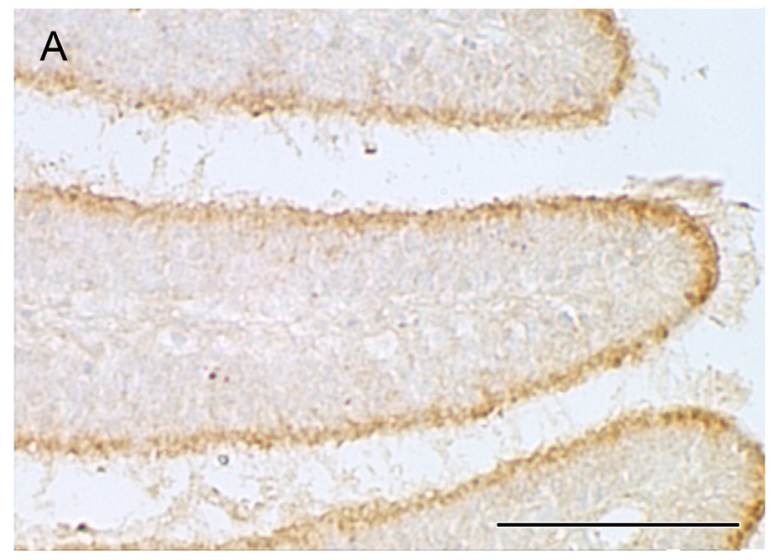

B

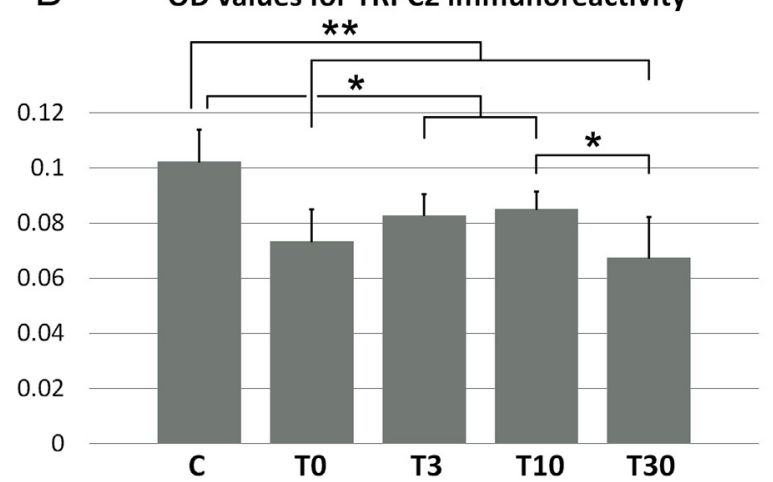

Fig. 4. TRPC2 immunohistochemistry in zebrafish olfactory epithelium before and after $30 \mu \mathrm{g} \mathrm{L}^{-1} \mathrm{Cu}^{2+}$ exposure. A) Along the sensory areas in the olfactory lamellae of control fish, the apical region of the olfactory epithelium contains the receptor cell endings which are stained by anti-TRPC2 antibody. Scale bar: $50 \mu \mathrm{m}$. B) Opti-cal density analysis of the olfactory epithelium surface and comparison between control and treated groups. C, control; T0, 0 days of recovery; T3, 3 days of recovery; T10, 10 days of recovery; T30, 30 days of recovery. Asterisks indicate significant differences: *, $\mathrm{P}<0.05$; ${ }^{* *}, \mathrm{P}<0.01$.

et al., 2004; Oka et al., 2012; Sato et al., 2005); thus it is considered nonspecific (Ahuja et al., 2013). A strong and specific marker, which could be used to recognize crypt neurons in zebrafish, is anti-TrkA antibody (Ahuja et al., 2013; Bettini et al., 2016), originally used by Catania et al. (2003). Consequently, in the present study, we used anti-TrkA to detect crypt cell population in zebrafish. Although crypt cell counting could suggest an increase in crypt cell number at the end of the exposure, statistical analysis excludes any significant difference in crypt cell number. Therefore, in our experiment, crypt cells appeared not affected by $\mathrm{Cu}^{2+}$ exposure at the concentration of $30 \mu \mathrm{g} \mathrm{L}^{-1}$. Crypt cells bear both cilia and microvilli, but these apical structures are contained in a deep concavity opening at the api-cal surface of the cell with a narrow gap and with possible limited access of substances from the mucous layer covering the epithelial surface. In cOSNs and mOSNs, microvilli and cilia, which appear to be the most sensitive structures, are directly exposed to the outer environment. It is possible that this different position protects the sensitive structures of crypt cells from environmental pollutants, such as heavy metals.

In anti-HuC/D immunostaining, statistical analysis of densitometric values showed that there was no significant difference in the number of neurons in the analyzed groups. Although cOSNs and mOSNs showed a clear staining decrease in their specific markers in T0 compared to the control, the statistically unvaried number of total neurons suggests the existence of undifferentiated neurons,

i.e. expressing neither $G \alpha$ olf nor TRPC2.
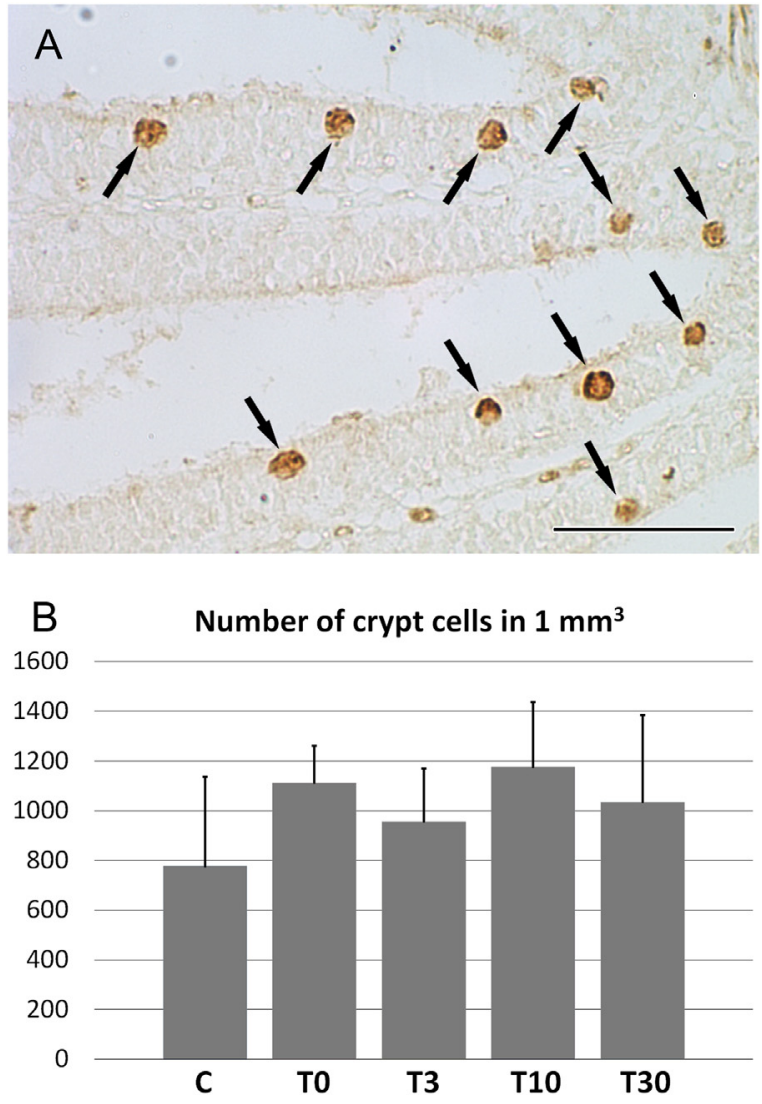

Fig. 5. TrkA immunohistochemistry in zebrafish olfactory epithelium before and after $30 \mu \mathrm{g} \mathrm{L}^{-1} \mathrm{Cu}^{2+}$ exposure. A) In control specimen, crypt cells (arrows) are present close to the surface of the olfactory epithelium in the sensory area of the olfactory lamellae. Scale bar: $50 \mu \mathrm{m}$. B) Density of crypt cells and comparison between control and treated groups. No significant differences result from the statistical analysis of data. C, control; T0, 0 days of recovery; T3, 3 days of recovery: T10, 10 days of recovery; T30, 30 days of recovery.

In T0 and T3, anti-PCNA immunostaining increased about 1.5 times compared to the control, whereas in T10 and T30 the immunostaining reverted to values statistically equivalent to the control. These data indicate an increase in the mitotic activity, which coincides with the decrease of $G \alpha$ olf and TRPC2 immunoreactivity. In the $\mathrm{OE}$, mitotic activity and neuronal differentiation take place physiologically throughout life to substitute OSNs, which come naturally to the end of their life span. In the OE, the mature OSNs downregulate the growth and differentiation of new recep-tor cells starting from neuronal progenitors (basal cells) in order to keep the size of their populations at a defined level (Wu et al., 2003). During $\mathrm{Cu}^{2+}$ exposure, OSNs may decrease their number due to degeneration (decrease in immunostaining) and during recovery, in water without addition of copper, they may gradually increase their number by proliferation and differentiation (increase in immunostaining). The $\mathrm{Cu}^{2+}$ exposure has removed the inhibi-tion and consequently activated the response of the germinal layer of the olfactory epithelium, a process already described in mouse (Ducray et al., 2002; Min et al., 2003). In Poecilia reticulata, using a monoclonal antibody against GAP-43, a phosphoprotein involved in neuronal differentiation, we demonstrated that, after mitosis, the new differentiating elements migrate from the epithelial basal layer and reach the upper layer in three days. These data from anti-GAP-43 are in agreement with those obtained by $3 \mathrm{H}$-thymidine in mice and anti-BrdU in the lacustrine sockeye salmon (Mackay-Sim and Kittel, 1991; Yanagi et al., 2004). 

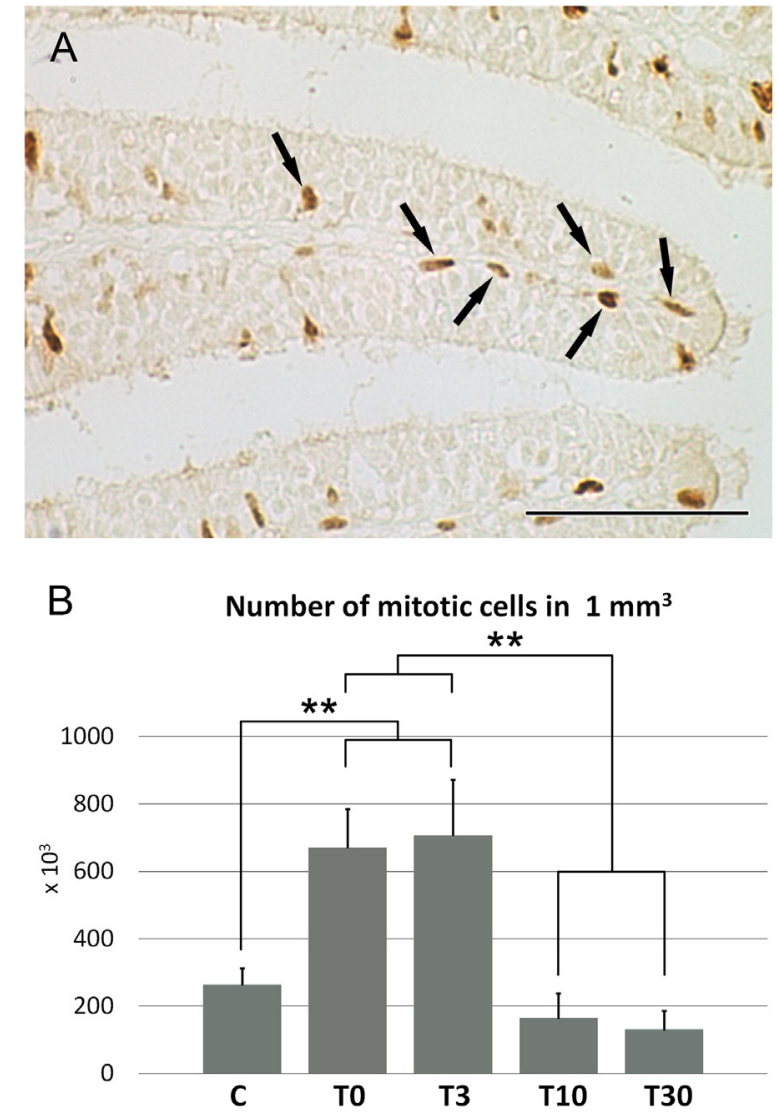

Fig. 6. PCNA immunohistochemistry in zebrafish olfactory epithelium before and after $30 \mu \mathrm{g} \mathrm{L}^{-1} \mathrm{Cu}^{2+}$ exposure. A) In control specimen, mitotic cells (arrows) are visible in the sensory area of the epithelium covering olfactory lamellae. Scale bar: $50 \mu$ $\mathrm{m}$. B) Density of dividing cells and comparison between control and treated groups. C, control; T0, 0 days of recovery; T3, 3 days of recovery; T10, 10 days of recovery; $\mathrm{T} 30,30$ days of recovery. Asterisks indicate significant differences: ${ }^{* *}, \mathrm{P}<0.01$.

In our study, the significantly increased value of anti- $\mathrm{G}_{\alpha \mathrm{olf}} \mathrm{OD}$ observed in T10 compared to T0 is indicative of the complete differ-entiation of cOSNs. Ciliated terminal knob differentiation is the final step of maturation of the dendritic branch of new receptor cells. The new olfactory cells require about 10 days to reach their com-plete maturation (Tilapia mariae, Bettini et al., 2006a; Oncorhynchus mykiss, Julliard et al., 1996).

The same experimental conditions can induce lesions with different extensions depending on the species (T. mariae, Bettini et al., 2006a; Poecilia reticulata, Bettini et al., 2006b; O. mykiss, Julliard et al., 1996). However, the time of differentiation from basal cells to mature ORNs showed no apparent difference in fish and mammals (Bettini et al., 2006a; Graziadei and Monti Graziadei, 1979; Michel et al., 1999). Moreover, receptor cell differentiation takes the same time in both axotomized and untreated olfactory organs (Salmo trutta, Moran et al., 1992; Oncorhynchus nerka, Yanagi et al., 2004). The present results for anti-G $\alpha$ olf and anti-PCNA permit us to hypothesize that a period of about ten days is required for cONS maturation also in zebrafish. Therefore, as previously supposed for $P$. reticulata (Bettini et al., 2006b), the time-course of new receptor cell development does not appear influenced by the type of experimental injury, even when it differently affects neuron populations (Iqbal and Byrd-Jacobs, 2010).

Although our results showing an increase in mitotic activity during recovery should indicate that $\mathrm{Cu}^{2+}$ exposure caused reduction in neuronal number, we could not exclude that some affected neurons survived. In this case, the heavy metal simply causes a decrease in antigen expression, while in the recovery period, in water without addition of copper, neurons gradually increase antigen expression again.

The exposure to $30 \mu \mathrm{g} \mathrm{L}^{-1} \mathrm{Cu}^{2+}$ caused no macroscopic effects in zebrafish. Specifically, during exposure and recovery, no animal died, no behavioral alteration was detected, and micro-anatomical and histological analyses revealed that olfactory rosettes and lamellae preserved their morphology. This is in accordance with our previous studies on Tilapia (Bettini et al., 2006a), in which $20 \mu$ $\mathrm{g} \mathrm{L}^{-1} \mathrm{Cu}^{2+}$ caused no histological alterations of the olfactory mucosa, whereas $40 \mu \mathrm{g} \mathrm{L}^{-1} \mathrm{Cu}^{2+}$ were followed by some alterations in the olfactory rosette.

In the present study on zebrafish, calretinin immunostaining showed an evident decrease in olfactory epithelium thickness at T0 stage. This is in accordance with the decrease in $\mathrm{G} \alpha$ olf and TRPC2 immunostaining, which could indicate a certain reduction in the number of cOSNs and mOSNs at TO. The increase in mitotic activ-ity revealed by PCNA immunostaining at T0 and the uniform high amount of total neurons, including still undifferentiated neurons, would be responsible for the gradual restoration of the epithelial thickness to normal values in T10 and T30.

In fish olfactory epithelium, non-neuronal cells are less affected by $\mathrm{Cu}$ ions (Julliard et al., 1993, 1996; Moran et al., 1992). In our study, anti-calretinin immunostaining revealed a different behavior of the sensory area between the lamellae of the dorsal half and those of the ventral half of the olfactory rosettes. Whereas in the dorsal lamellae, the sensory area appears increased only in T30 compared to the control, in the ventral lamellae, this increase is already significant in $\mathrm{T} 0$ and is maintained up to T30. These results indicate that $30 \mu \mathrm{g} \mathrm{L}^{-1} \mathrm{Cu}^{2+}$ treatment causes an increase in the sensory areas of the olfactory lamellae, in accordance with a functional recovery, after continuous $\mathrm{Cu}^{2+}$ exposure for up to $96 \mathrm{~h}$, demonstrated by behavioral and electrophysiological assays in Col-orado pikeminnow (Beyers and Farmer, 2001) and fathead minnow (Dew et al., 2012). However, in zebrafish, the lamellae of the dor-sal and ventral halves of the olfactory rosettes show different time of reaction. Calretinin immunostaining indicates a contribution of both cOSNs and mOSNs to the signal, but, considering $G \alpha$ olf and TRPC2 immunostaining, the delayed increase of sensory areas in dorsal lamellae could be attributed to a delayed increase of the cOSNs with negligible contribution by mOSNs. On the contrary, in the ventral lamellae, the early increase of sensory areas could be ascribed especially to mOSNs. Reduction in epithelium thickness and sensory area increase imply that during epithelium recov-ery immature neural cells can migrate into adjacent non-sensory regions. This event would especially affect ventral lamellae show-ing high sensory to non-sensory area ratio.

\section{Conclusions}

Fish are at risk of exposure to heavy metals introduced in the aquatic environment from various human activities and growing evidence supports that copper, even at low concentration, can cause deleterious effects on olfaction influencing behavior and hence ecology. Different sensitivity to copper exposure not only exists among species as reported in the literature, but also is present among different types of receptor neurons inside the olfactory epithelium as shown by the present study. Immunohistochemi-cal detection of molecular markers revealed a differential response of zebrafish OSNs to $30 \mu \mathrm{g} \mathrm{L}^{-1} \mathrm{Cu}^{2+}$ exposure. In particular, cOSNs turned out to be the most sensitive whereas mOSNs had a weaker response. Crypt neurons appeared unaffected.

Alsop and Wood $(2011,2013)$ reported that the disruption of ion uptake following metal exposure does not appear to be responsible for the acute toxicity, as previously suggested, but rather the toxic- 
ity is the result of total ion loss, mostly $\mathrm{Na}^{+}$. Moreover, $\mathrm{Cu}$ exposure can affect the transcriptions of both subunits of Na/K-ATPase in fish olfactory epithelium (Azizishirazi et al., 2015).

The underlying processes leading to these differences among receptor cells are not fully understood. Different functions were attributed to the three types of OSNs (Ahuja et al., 2013; Bazáes and Schmachtenberg, 2012; Biechl et al., 2016; Hamdani and Døving, 2006; Sato and Suzuki, 2001; Vielma et al., 2008). Moreover, many studies have focused on behavioral effects of $\mathrm{Cu}$ exposure in fish (Acosta et al., 2016; Poulsen et al., 2014; Scott and Sloman, 2004; Simonato et al., 2016; Sovová et al., 2014; Svecevičius, 2012; Tilton et al., 2011). Comparative studies addressing structure and func-tion of the different OSNs in the different species would greatly enhance our understanding of the mechanisms of olfaction, sup-plying additional information on neurophysiology, behavior and ecology of fish.

\section{Acknowledgments}

This work was supported by national public funds grant FFO2014FRA4 from the Italian Ministry of Education, University and Research (MIUR).

\section{References}

da S. Acosta, D., Danielle, N.M., Altenhofen, S., Luzardo, M.D., Costa, P.G., Bianchini, A., Bonan, C.D., da Silva, R.S., Dafre, A.L., 2016. Copper at low levels impairs memory of adult zebrafish (Danio rerio) and affects swimming performance of larvae. Comp. Biochem. Physiol. C: Toxicol. Pharmacol. 185-186, 122-130, http://dx.doi.org/10.1016/j.cbpc.2016.03.008.

Ahuja, G., Ivandić, I., Saltürk, M., Oka, Y., Nadler, W., Korsching, S.I., 2013. Zebrafish crypt neurons project to a single, identified mediodorsal glomerulus. Sci. Rep.

3, 2063, http://dx.doi.org/10.1038/srep02063.

Alsop, D., Wood, C.M., 2011. Metal uptake and acute toxicity in zebrafish: common mechanisms across multiple metals. Aquat. Toxicol. 105, 385-393, http://dx. doi.org/10.1016/j.aquatox.2011.07.010.

Alsop, D., Wood, C.M., 2013. Metal and pharmaceutical mixtures: is ion loss the mechanism underlying acute toxicity and widespread additive toxicity in zebrafish? Aquat. Toxicol. 140-141, 257-267, http://dx.doi.org/10.1016/j aquatox.2013.05.021.

Azizishirazi, A., Dew, W.A., Forsyth, H.L., Pyle, G.G., 2013. Olfactory recovery of wild yellow perch from metal contaminated lakes Ecotoxicol. Environ. Saf. 88,

42-47, http://dx.doi.org/10.1016/j.ecoenv.2012.10.015.

Azizishirazi, A., Dew, W.A., Bougas, B., Bernatchez, L., Pyle, G.G., 2015. Dietary sodium protects fish against copper-induced olfactory impairment. Aquat. Toxicol. 161, 1-9, http://dx.doi.org/10.1016/j.aquatox.2015.01.017.

Baier, H., Korsching, S., 1994. Olfactory glomeruli in the zebrafish form an invariant pattern and are identifiable across animals. J. Neurosci. 14, 219-230.

Baldwin, D.H., Sandahl, J.F., Labenia, J.S., Scholz, N.L., 2003. Sublethal effects of copper on coho salmon: impacts on nonoverlapping receptor pathways in the peripheral olfactory nervous system. Environ. Toxicol. Chem. 22, 2266-2274.

Baldwin, D.H., Tatara, C.P., Scholz, N.L., 2011. Copper-induced olfactory toxicity in salmon and steelhead: extrapolation across species and rearing environments. Aquat. Toxicol. 101, 295-297, http://dx.doi.org/10.1016/j.aquatox.2010.08.011.

Bazáes, A., Schmachtenberg, O., 2012. Odorant tuning of olfactory crypt cells from juvenile and adult rainbow trout. J. Exp. Biol. 215, 1740-1748, http://dx.doi. org/10.1242/jeb.067264.

Bettini, S., Ciani, F., Franceschini, V., 2006a. Recovery of the olfactory receptor neurons in the African Tilapia mariae following exposure to low copper level. Aquat. Toxicol. 76, 321-328, http://dx.doi.org/10.1016/j.aquatox.2005.10.009.

Bettini, S., Ciani, F., Franceschini, V., 2006b. Cell proliferation and growth-associated protein 43 expression in the olfactory epithelium in Poecilia

reticulata after copper solution exposure. Eur. J. Histochem. 50, 141-146. Bettini, S.,

Lazzari, M., Ferrando, S., Gallus, L., Franceschini, V., 2016.

Histopathological analysis of the olfactory epithelium of zebrafish (Danio rerio) exposed to sublethal doses of urea. J. Anat. 228, 59-69, http://dx.doi.org/10. 1111 /joa.12397.

Beyers, D.W., Farmer, M.S., 2001. Effects of copper on olfaction of colorado pikeminnow. Environ. Toxicol. Chem. 20, 907-912.

Biechl, D., Tietje, K., Gerlach, G., Wullimann, M.F., 2016. Crypt cells are involved in kin recognition in larval zebrafish. Sci. Rep. 6, 24590, http://dx.doi.org/10. 1038/srep24590.

Bondier, J.R., Michel, G., Propper, A., Badot, P.M., 2008. Harmful effects of cadmium on olfactory system in mice. Inhal. Toxicol. 20, 1169-1177, http://dx.doi.org/ $10.1080 / 08958370802207292$.

Braubach, O.R., Fine, A., Croll, R.P., 2012. Distribution and functional organization of glomeruli in the olfactory bulbs of zebrafish (Danio rerio). J. Comp. Neurol. 520, 2317-2339, http://dx.doi.org/10.1002/cne.23075.
Cardwell, R.D., Foreman, D.G., Payne, T.R., Wilbur, D.J., 1976. Acute toxicity of selenium dioxide to freshwater fishes. Arch. Environ. Contam. Toxicol. 4, 129-144.

Catania, S., Germanà, A., Laurà, A., Gonzalez-Martinez, T., Ciriaco, E., Vega, J.A 2003. The crypt neurons in the olfactory epithelium of the adult zebrafish express TrkA-like immunoreactivity. Neurosci. Lett. 350, 5-8, http://dx.doi. org/10.1016/S0304-3940(03)00751-1.

Davis, A.P., Shokouhian, M., Ni, S., 2001. Loading estimates of lead, copper, cadmium, and zinc in urban runoff from specific sources. Chemosphere 44 , 997-1009.

Dew, W.A., Wood, C.M., Pyle, G.G., 2012. Effects of continuous copper exposure and calcium on the olfactory response of fathead minnows. Environ. Sci. Technol. 46, 9019-9026, http://dx.doi.org/10.1021/es300670p.

Dew, W.A., Azizishirazi, A., Pyle, G.G., 2014. Contaminant-specific targeting of olfactory sensory neuron classes: connecting neuron class impairment with behavioural deficits. Chemosphere 112, 519-525, http://dx.doi.org/10.1016/j. chemosphere.2014.02.047.

Ducray, A., Bondier, J.R., Michel, G., Bon, K., Millot, J.L., Propper, A., Kastner, A 2002. Recovery following peripheral destruction of olfactory neurons in young and adult mice. Eur. J. Neurosci. 15, 1907-1917, http://dx.doi.org/10.1046/j. 1460-9568.2002.02044. $\mathrm{x}$

Eisthen, H.L., Polese, G., 2007. Evolution of vertebrate olfactory subsystems. In: Kaas, J.H., Bullock, T.H. (Eds.), Evolution of Nervous Systems, Non-mammalian Vertebrates, vol. 2. Academic Press, Amsterdam, pp. 355-406.

Eisthen, H.L., 1992. Phylogeny of the vomeronasal system and of receptor cell types in the olfactory and vomeronasal epithelia of vertebrates. Microsc. Res. Tech. 23, 1-21, http://dx.doi.org/10.1002/jemt.1070230102.

Ferrando, S., Bottaro, M., Gallus, L., Girosi, L., Vacchi, M., Tagliafierro, G., 2006. Observations of crypt neuron-like cells in the olfactory epithelium of a cartilaginous fish. Neurosci. Lett. 403, 280-282, http://dx.doi.org/10.1016/j. neulet.2006.04.056.

Ferrando, S., Bottaro, M., Gallus, L., Girosi, L, Vacchi, M., Tagliafierro, G., 2007. First detection of olfactory marker protein (OMP) immunoreactivity in the olfactory epithelium of a cartilaginous fish. Neurosci. Lett. 413, 173-176, http://dx.doi. $\operatorname{org} / 10.1016 /$ j.neulet.2006.11.051.

Ferrando, S., Gallus, L., Gambardella, C., Amaroli, A., Vallarino, M., Tagliafierro, G., 2011. Immunolocalization of $G$ protein alpha subunits in the olfactory system of Polypterus senegalus (Cladistia, Actinopterygii). Neurosci. Lett. 499, 127-131, http://dx.doi.org/10.1016/j.neulet.2011.05.052.

Gayoso, J.Á., Castro, A., Anadón, R., Manso, M.J., 2011. Differential bulbar and extrabulbar projections of diverse olfactory receptor neuron populations in the adult zebrafish (Danio rerio). J. Comp. Neurol. 519, 247-276, http://dx.doi.org/ $10.1002 /$ cne.22518.

Gayoso, J., Castro, A., Anadón, R., Manso, M.J., 2012. Crypt cells of the zebrafish Danio rerio mainly project to the dorsomedial glomerular field of the olfactory bulb. Chem. Senses 37, 357-369, http://dx.doi.org/10.1093/chemse/bjr109.

Germanà, A., Montalbano, G., Laurà, R., Ciriaco, E., del Valle, M.E., Vega, J.A., 2004. S100 protein-like immunoreactivity in the crypt olfactory neurons of the adult zebrafish. Neurosci. Lett. 371, 196-198, http://dx.doi.org/10.1016/j.neulet. 2004.08.077.

Germanà, A., Paruta, S., Ochoa-Erena0, G.P., Ochoa-Erena, F.J., Montalbano, G., Vega, J.A., 2007. Differential distribution of S100 protein and calretinin in mechanosensory and chemosensory cells of adult zebrafish (Danio rerio). Brain Res. 1162, 48-55, http://dx.doi.org/10.1016/j.brainres.2007.05.070.

Good, J.C., 1993. Roof runoff as a diffuse source of metals and aquatic toxicity in storm water. Water Sci. Technol. 28 (3-5), 317-321.

Graziadei, P.P.C., Monti Graziadei, G.A., 1979. Neurogenesis and neuron regeneration in the olfactory system of mammals. I. Morphological aspects of differentiation and structural organization of the olfactory sensory neurons. J. Neurocytol. 8, 1-18.

Green, W.W., Zielinski, B.S., 2013. Chemoreception. In: Evans, D.H., Claiborne, J.B., Currie, S. (Eds.), The Physiology of Fishes. , fourth ed. CRC Press, Boca Raton, pp.

345-373.

Hamdani, H., Døving, K.B., 2006. Specific projection of the sensory crypt cells in the olfactory system in crucian carp, Carassius carassius. Chem. Senses 31, 63-67, http://dx.doi.org/10.1093/chemse/bjj006.

Hamdani, E.H., Døving, K.B., 2007. The functional organization of the fish olfactory system. Prog. Neurobiol. 82, 80-86, http://dx.doi.org/10.1016/j.pneurobio. 2007.02.007.

Hansen, A., Finger, T.E., 2000. Phyletic distribution of crypt-type olfactory receptor neurons in fishes. Brain Behav. Evol. 55, 100-110, http://dx.doi.org/10.1159/ 000006645 .

Hansen, A., Zeiske, E., 1998. The peripheral olfactory organ of the zebrafish, Danio rerio: an ultrastructural study. Chem. Senses 23 (1), 39-48, http://dx.doi.org/

10.1093/chemse/23.1.39.

Hansen, A., Zielinski, B.S., 2005. Diversity in the olfactory epithelium of bony fishes: development, lamellar arrangement, sensory neuron cell types and transduction components. J. Neurocytol. 34, 183-208, http://dx.doi.org/10. 1007/s11068-005-8353-1.

Hill, A.J., Teraoka, H., Heideman, W., Peterson, R.E., 2005. Zebrafish as a model vertebrate for investigating chemical toxicity. Toxicol. Sci. 86, 6-19, http://dx doi.org/10.1093/toxsci/kfi110.

Iqbal, T., Byrd-Jacobs, C., 2010. Rapid degeneration and regeneration of the zebrafish olfactory epithelium after Triton X-100 application. Chem. Senses 35, 351-361, http://dx.doi.org/10.1093/chemse/bjq019. 
Jenkins, P.M., McEwen, D.P., Martens, J.R., 2009. Olfactory cilia: linking sensory cilia function and human disease. Chem. Senses 34, 451-464, http://dx.doi.org/10. 1093/chemse/bjp020.

Julliard, A.K., Saucier, D., Astic, L., 1993. Effects of chronic lowlevel copper exposure on ultrastructure of the olfactory system in rainbow trout (Oncorhynchus mykiss). Histol. Histopathol. 8, 665-672.

Julliard, A.K., Saucier, D., Astic, L., 1996. Time-course of apoptosis in the olfactory epithelium of rainbow trout exposed to a low copper level. Tissue Cell 28, 367-377, http://dx.doi.org/10.1016/S0040-8166(96)80023-1.

Katagi, T., 2010. Bioconcentration, bioaccumulation, and metabolism of pesticides in aquatic organisms. Rev. Environ. Contam. Toxicol. 204, 1-132, http://dx.doi. org/10.1007/978-1-4419-1440-8_1.

Kiaune, L., Singhasemanon, N., 2011. Pesticidal copper (I) oxide: environmental fate and aquatic toxicity. In: Whitacre, D.M. (Ed.), Rev. Environ. Contam. Toxicol., vol. 213, pp. 1-26, http://dx.doi.org/10.1007/978-1-4419-9860-6 1.

Klečka, G., Persoon, C., Currie, R., 2010. Chemicals of emerging concern in the great lakes basin: an analysis of environmental exposures. Rev. Environ. Contam. Toxicol. 207, 1-93, http://dx.doi.org/10.1007/978-1-4419-6406-9 1.

Kolmacov, N.N., Hubbard, P.C., Lopes, O., Canario, A.V., 2009. Effect of acute copper sulfate exposure on olfactory responses to amino acids and pheromones in goldfish (Carassius auratus). Environ. Sci. Technol. 43, 8393-8399, http://dx. doi.org/10.1021/es901166m.

Lürling, M., Scheffer, M., 2007. Info-disruption:pollution and the transfer of chemical information between organisms. Trends Ecol. Evol. 22, 374-379, http://dx.doi.org/10.1016/j.tree.2007.04.002.

Laberge, F., Hara, T.J., 2001. Neurobiology of fish olfaction: a review. Brain Res. Rev. $36,46-59$.

Lammer, E., Carr, G.J., Wendler, K., Rawlings, J.M., Belanger, S.E., Braunbeck, T 2009a. Is the fish embryo toxicity test (FET) with the zebrafish (Danio rerio) a potential alternative for the fish acute toxicity test? Comp. Biochem. Physiol. C: Toxicol. Pharmacol. 149, 196-209, http://dx.doi.org/10.1016/j.cbpc.2008.11. 006 .

Lammer, E., Kamp, H.G., Hisgen, V., Koch, M., Reinhard, D., Salinas, E.R., Wendler, K. Zok, S., Braunbeck, T., 2009b. Development of a flow-through system for the fish embryo toxicity test (FET) with the zebrafish (Danio rerio). Toxicol. in Vitro 23, 1436-1442, http://dx.doi.org/10.1016/j.tiv.2009.05.014.

Lazzari, M., Bettini, S., Ciani, F., Franceschini, V., 2007. Light and transmission electron microscopy study of the peripheral olfactory organ of the guppy, Poecilia reticulata (Teleostei, Poecilidae). Microsc. Res. Tech. 70, 782-789, http://dx.doi.org/10.1002/jemt.20487.

Lazzari, M., Bettini, S., Franceschini, V., 2016. Immunocytochemical characterisation of ensheathing glia in the olfactory and vomeronasal systems of Ambystoma mexicanum (Caudata: Ambystomatidae). Brain Struct. Funct. 221, 955-967, http://dx.doi.org/10.1007/s00429-014-0949-8.

Mackay-Sim, A., Kittel, P., 1991. Cell dynamics in the adult mouse olfactory epithelium: a quantitative autoradiographic study. J. Neurosci. 11, 979-984.

McIntyre, J.K., Baldwin, D.H., Meador, J.P., Scholz, N.L., 2008. Chemosensory deprivation in juvenile coho salmon exposed to dissolved copper under varying water chemistry conditions. Environ. Sci. Technol. 42, 1352-1358. Michel, V., Monnier, Z., Cvetkovic, V., Math, F., 1999. Organotypic culture of neuroepithelium attached to olfactory bulb from adult mouse as a tool to stùdy neuronal regeneration after $\mathrm{ZnSO}_{4}$ neuroepithelial trauma. Neurosci. Lett. 1999 (271), 195-198, http://dx.doi.org/10.1016/S0304-3940(99)00551-0.

Min, Y.G., Kim, J.W., Hong, S.C., Dhong, H.J., Jarin, P.R., Jin, Y., 2003. Pathogenetic mechanism of olfactory cell injury after exposure to sulfur dioxide in mice. Laryngoscope 113, 2157-2162, http:// dx.doi.org/10.1097/00005537-200312000-00020.

Miyasaka, N., Wanner, A.A., Li, J., Mack-Bucher, J., Genoud, C., Yoshihara, Y., Friedrich, R.W., 2013. Functional development of the olfactory system in zebrafish. Mech. Dev. 130, 336-346, http://dx.doi.org/10.1016/j.mod.2012.09. 001.

Moran, D.T., Rowley III, J.C., Aiken, G.R., Jafek, B.W., 1992. Ultrastructural neurobiology of the olfactory mucosa of the brown trout, Salmo trutta. Microsc. Res. Technol. 23, 28-48, http://dx.doi.org/10.1002/jemt.1070230104.

Nelson, J.S., 2006. Fishes of the World, fourth ed. John Wiley \& Sons, New York.

Oka, Y., Saraiva, L.R., Korsching, S.I., 2012. Crypt neurons express a single V1R-related ora gene. Chem. Senses 37, 219-227, http://dx.doi.org/10.1093/ chemse/bjr095.

Poulsen, S.B., Svendsen, J.C., Aarestrup, K., Malte, H., 2014. Calcium-dependent behavioural responses to acute copper exposure in Oncorhynchus mykiss. J. Fish Biol. 84, 1326-1339, http://dx.doi.org/10.1111/jfb.12356.

Pyle, G.G., Mirza, R.S., 2007. Copper-impaired chemosensory function and behavior in aquatic animals. Hum. Ecol. Risk Assess. 13, 492-505, http://dx.doi.org/10. 1080/10807030701340995.

Sandahl, J.F., Baldwin, D.H., Jenkins, J.J., Scholz, N.L., 2007. A sensory system at the interface between urban stormwater runoff and salmon survival. Environ. Sci. Technol. 41, 2998-3004.

Sato, K., Suzuki, N., 2001. Whole-cell response characteristics of ciliated and microvillous olfactory receptor neurons to amino acids, pheromone candidates and urine in rainbow trout. Chem. Senses 26, 1145-1156.

Sato, Y., Miyasaka, N., Yoshihara, Y., 2005. Mutually exclusive glomerular innervation by two distinct types of olfactory sensory neurons revealed in transgenic zebrafish. J. Neurosci. 25, 4889-4897, http://dx.doi.org/10.1523/ JNEUROSCI. 0679-05.2005
Schwarzenbach, R.P., Egli, T., Hofstetter, T.B., von Gunten, U., Wehrli, B., 2010. Global water pollution and human health. Annu. Rev. Environ. Resour. 35, 109-136, http://dx.doi.org/10.1146/annurev-environ-100809-125342.

Scott, G.R., Sloman, K.A., 2004. The effects of environmental pollutants on complex fish behaviour: integrating behavioural and physiological indicators of toxicity. Aquat. Toxicol. 68, 369-392, http://dx.doi.org/10.1016/j.aquatox.2004.03.016.

Scott, G.R., Sloman, K.A., Rouleau, C., Wood, C.M., 2003. Cadmium disrupts behavioural and physiological responses to alarm substance in juvenile rainbow trout (Oncorhynchus mykiss). J. Exp. Biol. 206, 1779-1790.

Segner, H., 2009. Zebrafish (Danio rerio) as a model organism for investigating endocrine disruption. Comp. Biochem. Physiol. C: Toxicol. Pharmacol. 149 187-195, http://dx.doi.org/10.1016/j.cbpc.2008.10.099.

Shaw, B.J., Handy, R.D., 2011. Physiological effects of nanoparticles on fish: a comparison of nanometals versus metal ions. Environ. Int. 37, 1083-1097, http://dx.doi.org/10.1016/j.envint.2011.03.009.

Simonato, J.D., Mela, M., Doria, H.B., Guiloski, I.C., Randi, M.A., Carvalho, P.S., Meletti, P.C., Silva de Assis, H.C., Bianchini, A., Martinez, C.B., 2016. Biomarkers of waterborne copper exposure in the neotropical fish Prochilodus lineatus. Aquat. Toxicol. 170, 31-41, http://dx.doi.org/10.1016/j.aquatox.2015.11.012.

Soller, J., Stephenson, J., Olivieri, K., Downing, J., Olivieri, A.W., 2005. Evaluation of seasonal scale first flush pollutant loading and implications for urban runoff management. J. Environ. Manage. 76, 309-318, http://dx.doi.org/10.1016/j. jenvman.2004.12.007.

Song, L., Vijver, M.G., Peijnenburg, W.J., Galloway, T.S., Tyler, C.R., 2015. A comparative analysis on the in vivo toxicity of copper nanoparticles in three species of freshwater fish. Chemosphere 139, 181-189, http://dx.doi.org/10. 1016/j.chemosphere.2015.06.021.

Sorensen, P.W., Caprio, J., 1998. Chemoreception. In: Evans, D.H. (Ed.), The Physiology of Fishes. CRC Press, Boca Raton (FL), pp. 375-405.

Sovová, T., Boyle, D., Sloman, K.A., Vanegas Pérez, C., Handy, R.D., 2014. Impaired behavioural response to alarm substance in rainbow troutexposed to copper nanoparticles. Aquat. Toxicol. 152, 195-204, http://dx.doi.org/10.1016/j. aquatox.2014.04.003.

Svecevičius, G., 2012. Avoidance of copper and zinc by rainbow trout Oncorhynchus mykiss pre-exposed to copper. Bull. Environ. Contam. Toxicol. 88, 1-5, http:// dx.doi.org/10.1007/s00128-011-0426-5.

Tierney, K.B., Baldwin, D.H., Hara, T.J., Ross, P.S., Scholz, N.L., Kennedy, C.J., 2010. Olfactory toxicity in fishes. Aquat. Toxicol. 96, 2-26, http://dx.doi.org/10.1016/ j.aquatox.2009.09.019.

Tilton, F., Tilton, S.C., Bammler, T.K., Beyer, R., Farin, F., Stapleton, P.L., Gallagher, E.P., 2008. Transcriptional biomarkers and mechanisms of copper-induced olfactory injury in zebrafish. Environ. Sci. Technol. 42, 9404-9411.

Tilton, F.A., Bammler, T.K., Gallagher, E.P., 2011. Swimming impairment and acetylcholinesterase inhibition in zebrafish exposed to copper or chlorpyrifos separately, or as mixtures. Comp. Biochem. Physiol. C: Toxicol. Pharmacol. 153, 9-16, http://dx.doi.org/10.1016/j.cbpc.2010.07.008.

Vielma, A., Ardiles, A., Delgado, L., Schmachtenberg, O., 2008. The elusive crypt olfactory receptor neuron: evidence for its stimulation by amino acids and cAMP pathway agonists. J. Exp. Biol. 211, 2417-2422, http://dx.doi.org/10. $1242 /$ jeb.018796.

Wang, H., Liang, Y., Li, S., Chang, J., 2013a. Acute toxicity, respiratory reaction, and sensitivity of three cyprinid fish species caused by exposure to four heavy metals. PLoS One 8, e65282, http://dx.doi.org/10.1371/journal.pone.0065282.

Wang, L., Espinoza, H.M., Gallagher, E.P., 2013b. Brief exposure to copper induces apoptosis and alters mediators of olfactory signal transduction in coho salmon. Chemosphere 93, 2639-2643, http://dx.doi.org/10.1016/j.chemosphere.2013. 08.044 .

Wang, L., Bammler, T.K., Beyer, R.P., Gallagher, E.P., 2013c. Copper-induced deregulation of microRNA expression in the zebrafish olfactory system. Environ. Sci. Technol. 47, 7466-7474, http://dx.doi.org/10.1021/es400615q

Wu, H.H., Ivkovie, S., Murray, R.C., Jaramillo, S., Lyons, K.M., Johnson, J.E., Calof, A.E. 2003. Autoregulation of neurogenesis by GDF11. Neuron 37, 197-207, http:// dx.doi.org/10.1016/S0896-6273(02)01172-8.

Wyatt, T.D., 2010. Pheromones and signature mixtures: defining species-wide signals and variable cues for identity in both invertebrates and vertebrates. J. Comp. Physiol. A Neuroethol. Sens. Neural. Behav. Physiol. 196, 685-700, http://dx.doi.org/10.1007/s00359-010-0564-y.

Yamamoto, M., 1982. Comparative morphology of the peripheral olfactory organ in teleosts. In: Hara, T.J. (Ed.), Chemoreception in Fishes. Elsevier, Los Angeles, pp. 39-59.

Yanagi, S., Kudo, H., Doi, Y., Yamauchi, K., Ueda, H., 2004. Immunohistochemical demonstration of salmon olfactory glutathione $S$-transferase class pi (N24) in the olfactory system of lacustrine sockeye salmon during ontogenesis and cell proliferation. Anat. Embryol. 208, 231-238, http://dx.doi.org/10.1007/ s00429-004-0392-3.

Zeiske, E., Theisen, B., Breucker, H., 1992. Structure, development, and evolutionary aspects of the peripheral olfactory system. In: Hara, T.J. (Ed.), Fish Chemoreception. Springer, Amsterdam, pp. 13-39, http://dx.doi.org/10.1007/ 978-94-011-2332-7_2. 